\title{
Investigation and Preparation of the Plastering Mortar for Autoclaved Aerated Blocks Walls
}

\author{
Tao Feng $\mathbb{D}^{\text {, Lingling } \mathrm{Xu}}{ }^{*}$, Xin Shi, Jian Han and Pan Zhang
}

check for updates

Citation: Feng, T.; Xu, L.; Shi, X.; Han, J.; Zhang, P. Investigation and Preparation of the Plastering Mortar for Autoclaved Aerated Blocks Walls. Crystals 2021, 11, 175. https:// doi.org/10.3390/cryst11020175

Received: 20 January 2021

Accepted: 5 February 2021

Published: 10 February 2021

Publisher's Note: MDPI stays neutral with regard to jurisdictional claims in published maps and institutional affiliations.

Copyright: (C) 2021 by the authors Licensee MDPI, Basel, Switzerland. This article is an open access article distributed under the terms and conditions of the Creative Commons Attribution (CC BY) license (https:// creativecommons.org/licenses/by/ $4.0 /)$.

\author{
College of Materials Science and Engineering, Nanjing Tech University, Nanjing 211800, China; \\ 201861103005@njtech.edu.cn (T.F.); 201961103066@njtech.edu.cn (X.S.); 201861203009@njtech.edu.cn (J.H.); \\ 201961103072@njtech.edu.cn (P.Z.) \\ * Correspondence: 0235@njtech.edu.cn; Tel.: +86-139-5184-6173
}

\begin{abstract}
The increase in the use of aerated concrete blocks (AAB) in construction walls has increased the demand for specialized plastering mortar, which should have the characteristics of high water retention, low water absorption, low thermal conductivity and high toughness. This study scrutinized the potential of expanded and vitrified small ball (EVSB) and expanded perlite as lightweight aggregates, and the beneficial effect of a modifying additive based on a mixture of ethylene-vinyl acetate (EVA), hydroxypropyl methylcellulose (HPMC) and fibers has been proved. The dry density, consistency, water absorption, mechanical strength, pore characteristics and micro morphology of the plaster mortar were evaluated. It is manifested by enhanced toughness, reduced dry density, and optimized pore structure characteristics. The relationship between mass water absorption and freeze-thaw cycle resistance is established, which shows that when the mass water absorption is $20 \%$, the mortar exhibits better freeze resistance. After 25 freeze-thaw cycle tests, the mass loss was $0.26 \%$ and the strength loss was $1.41 \%$. Through the comparison of test results, a new composition of plastering mortar is provided: cement: fly ash: water: heavy calcium carbonate: quartz sand: EVSB: EVA: HPMC (100,000 mPa.s): fiber = 70: 30: 76: 12: 250: 24: 2: 0.3: 0.2 .
\end{abstract}

Keywords: plastering mortar; autoclaved aerated blocks; mixture ratio design; expanded and vitrified small ball; mechanical properties; workability; durability

\section{Introduction}

Autoclaved aerated blocks (AABs) have been used in load-bearing and non-loadbearing structures of buildings since the mid-1920s, because of its lower density, good fire resistance, excellent sound insulation and thermal insulation [1], relative excellent impermeability [2] and high resource utilization efficiency [3,4]. AABs are produced through the autoclaving of raw materials, which mainly include calcareous materials, siliceous materials, additives, expanding agents (normally aluminum powder), and water [5]. Then, these autoclaved blocks would be cut to meet the suitable size for use. This would allow continuous capillary pores to be easily formed on the cut surface of AABs, while pores in the interior would be closed and discontinuous. This means that AABs can easily absorb water at the surface, but the degree of water absorption and relieving humidity is very slow [6]. It was found that the single-sided continuous water absorption of AABs with a density of $500 \mathrm{~kg} / \mathrm{m}^{3}$ is $10 \%$ at 21 days. The equilibrium moisture content of AABs ranges within 3-4\% at atmospheric environment with a relative humidity of $43 \%$, the actual drying shrinkage value is $0.1-0.2 \mathrm{~mm} / \mathrm{m}$ [5]. However, the re-wetting of AABs by external moisture would increase the drying shrinkage. Hence, mortar for the AABs should be characterized by high water retention [6,7] for fresh mortar, and low water absorption capacity [7] for hardened mortar.

Previous researchers have identified that cellulose and polymers (liquid resins, latexes, re-dispersible powders and water-soluble homopolymers or copolymers) can improve the water retention capacity of mortar [6,8]. Meanwhile, these also have a positive effect on the 
bond strength of the mortar [9]. Compared to the reference sample, when the content of re-dispersible emulsion powder was $1.2 \%$, the tensile bond strength increased by $18.9 \%$, and when the cellulose content was $0.2 \%$, the tensile bond strength increased by $85.3 \%$ [10]. However, the high bonding strength of the plaster mortar was not necessary, because the $\mathrm{AABs}$ are lightweight, porous, and low-density materials. Without changing the surface characteristics of AABs, a thin layer of cement slurry coating was applied to the block surface. Ordinary low-strength mortar can produce a good bonding effect $[9,11]$. Hence, for the plastering mortar, cellulose and polymers play a more important role in preventing cracking, increasing toughness [10,12-14], and improving serviceability [10]. Furthermore, the independent tiny spherical bubbles generated by the stirring of the mortar mixed with polymer and cellulose enhance the resistance of the mortar to damage caused by freeze-thaw cycles.

As presented in Figure 1a, the typical insulation walls used in China consist of a load-bearing AAB wall (number 1), a plastering mortar layer (number 2), a thermal insulation layer (number 4), an anti-cracking protective layer (numbers 6, 7, and 8), and a finishing layer (number 9). Many facts [15-18] have proven that this compound structure is scientific. Because of the fact that the thermal conductivity of the masonry mortar used to bond $\mathrm{AABs}$ is much higher than that of AABs [9], the existence of these masonry joints leads to the formation of "thermal bridges" $[19,20]$, as presented in Figure 1b. Therefore, it is necessary to reduce the heat loss caused by thermal bridges. The formation of the plaster layer of AABs from lightweight aggregates was considered to be the key to solving the "thermal bridges" effect [21,22]. Researchers have explored the potential of cork granules [23], perlite microspheres [24], expanded and vitrified small ball [25], air entraining agents [26,27], expanded vermiculite [28], phase change material [29], and expanded polystyrene beads [30]. Li et al. [18] concluded that the heat transfer coefficient of plastering mortar is $0.48 \mathrm{~W} /(\mathrm{m} \cdot \mathrm{K})$, in which expanded perlite, vitrified microsphere, and $0.04 \%$ polypropylene fiber were added to prevent the shrinkage and cracking of the mortar.

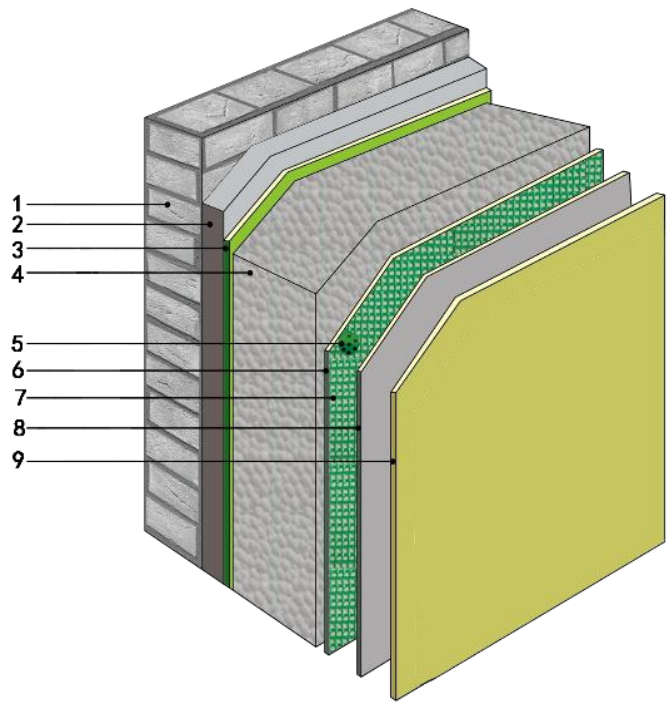

(a)

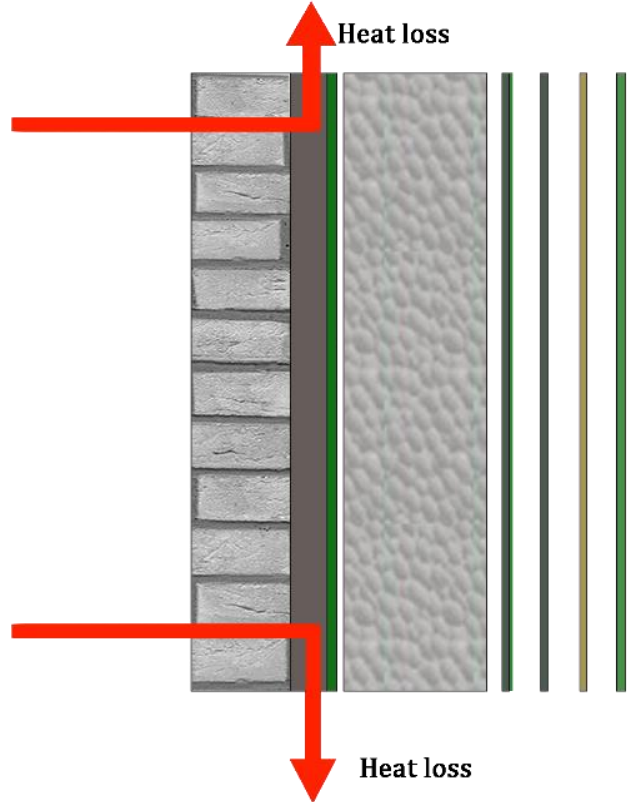

(b)

Figure 1. Schematic diagram. (a) A typical insulation wall in China. 1-AAB wall, 2-plastering mortar layer, 3-adhesive layer, 4-exterior insulation layer, 5-anchor bolt, 6-crack resistant glue, 7- fiberglass mesh, 8- crack resistant glue, 9- flexible water resistant putty; (b) form of the thermal bridge. 
The average density for commonly used AABs ranges within $400-600 \mathrm{~kg} / \mathrm{m}^{3}$. For the plastering of $\mathrm{AAB}$ walls, mortars made from lightweight aggregates are widely used at present, and the average density ranges within $1000-1400 \mathrm{~kg} / \mathrm{m}^{3}$. This brings a discrepancy in the deformation characteristics between the mortar and $\mathrm{AAB}$, resulting in the debonding through internal stresses at the interface joint between the $\mathrm{AAB}$ wall and plastering mortar layer. In this view, the mortar for the plastering of $A A B$ walls should be characterized by high toughness. Cyclic shear tests were employed by researchers to prove that plastering mortar with high toughness can improve the stability of the AAB wall structure [31].

In this paper, in order to develop the plastering for $A A B$ walls, the mortar was modified by compositing EVSB, fibers, ethylene-vinyl acetate (EVA), and hydroxypropyl methylcellulose (HPMC). Physical properties of the modified mortar, which included dry density, water absorption, water retention, compressive strength, and flexural strength were evaluated. The technical parameters and performance improvement mechanism were clarified in this study to provide a technical reference for the application field.

\section{Experimental}

\subsection{Raw Materials}

A compound cementitious system composed of P.II 52.5 type Portland Cement (Onada Cement Corp, Nanjing, China) and Class II fly ash (Ordos, China) was used in this experiment. Table 1 shows the chemical composition of cement and fly ash. Figure 2 presents the XRD pattern of fly ash. The physical properties and the particle size distribution of the expanded and vitrified small ball (EVSB) are listed in Tables 2 and 3. Dry and clean quartz sand with a continuous particle size of $0.154-0.500 \mathrm{~mm}$ was used as aggregate for the mortar. Heavy calcium carbonate was used as the filling material, which has an average particle size of $0.0455 \mathrm{~mm}$ and a bulk density of $1080 \mathrm{~kg} / \mathrm{m}^{3}$. The appearance of hydroxypropyl methylcellulose (HPMC) was white powder with three viscosities of 50,000 $\mathrm{mPa} \cdot \mathrm{s}$, $100,000 \mathrm{mPa} \cdot \mathrm{s}$, and 150,000 $\mathrm{mPa} \cdot \mathrm{s}$. The re-dispersible emulsion powder appeared as a white solid powder was the ethylene-vinyl acetate copolymer (EVA VINNAPAS-5011L). The length of the polypropylene fiber used in this experiment was $3 \mathrm{~mm}$ and $6 \mathrm{~mm}$, respectively.

Table 1. Chemical composition of cementitious materials (wt.\%).

\begin{tabular}{ccccccccc}
\hline Oxide & $\mathrm{SiO}_{\mathbf{2}}$ & $\mathrm{Al}_{\mathbf{2}} \mathbf{O}_{\mathbf{3}}$ & $\mathrm{Fe}_{\mathbf{2}} \mathbf{O}_{\mathbf{3}}$ & $\mathbf{C a O}$ & $\mathbf{M g O}$ & $\mathbf{S O}_{3}$ & $\mathbf{K}_{\mathbf{2}} \mathbf{O}$ & L.O.I \\
\hline Cement & 20.87 & 4.42 & 2.89 & 63.66 & 0.94 & 2.10 & 0.51 & 3.30 \\
Fly ash & 46.73 & 37.07 & 6.27 & 2.55 & 0.82 & 0.38 & 0.54 & 3.60 \\
\hline
\end{tabular}

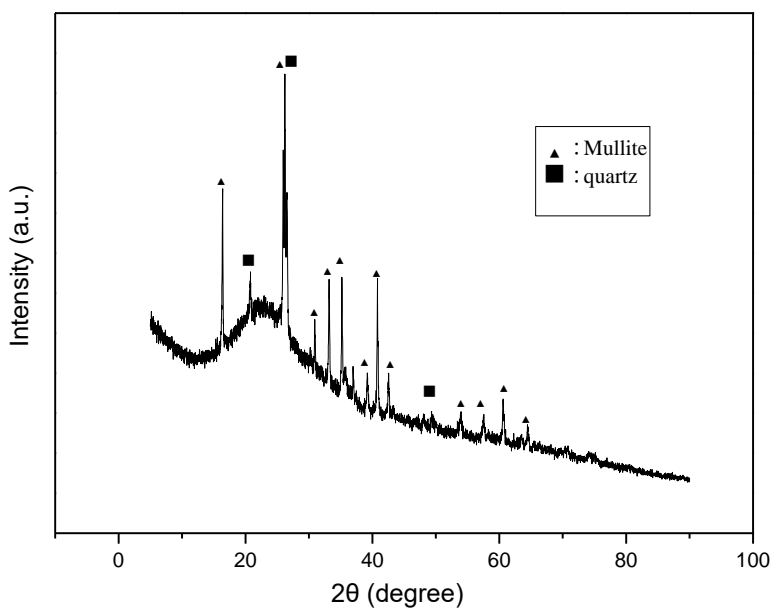

Figure 2. XRD pattern of the fly ash. 
Table 2. Physical properties of the expanded and vitrified small ball (EVSB).

\begin{tabular}{cc}
\hline Physical Properties & Measurements \\
\hline Bulk Density $/ \mathrm{kg} / \mathrm{m}^{3}$ & 150 \\
Thermal Conductivity $/ \mathrm{W} / \mathrm{m} \cdot \mathrm{K}$ & $0.0284-0.0540$ \\
Volumetric Water Absorption $/ \%$ & $20-50$ \\
\hline
\end{tabular}

Table 3. Particle size distribution of the EVSB.

\begin{tabular}{ccccc}
\hline Particle Size $/ \mathrm{mm}$ & $<0.50$ & $0.50-0.63$ & $0.63-0.80$ & $0.80-1.20$ \\
\hline Mass Percentage $/ \%$ & 13.92 & 15.88 & 51.55 & 18.65 \\
\hline
\end{tabular}

\subsection{Mix Proportion}

The proportion of various materials in the mixture was calculated as the mass percentage. Cementitious materials, heavy calcium carbonate, and sand were mixed at a constant ratio (1.00:0.12:2.50). The additional levels of EVSB was $20 \%, 22 \%, 24 \%, 26 \%$, and $28 \%$, by mass of the binder, respectively. The dosage of the EVA was set as $1 \%, 2 \%, 3 \%, 4 \%$, and $5 \%$ of the cementitious materials. The dosage of the HPMC with different viscosities was set as $0 \%, 0.1 \%, 0.2 \%, 0.3 \%, 0.4 \%$, and $0.5 \%$ of the binder. The water/binder ratio (ratio of water to the total mass of fly ash and cement) was set as $0.68,0.72,0.76,0.80$, and 0.84 . The cement and fly ash were weighed and mixed well (the mass ratio of cement and fly ash were 90:10, 80:20, 70:30, 60:40, 50:50). Then, the mixture was mixed with the heavy calcium carbonate, EVSB, EVA, and HPMC. Afterwards, water was mixed with the solid mixtures, and stirred at high speed for three minutes. Finally, the fibers were added into the above-mentioned mixture, and stirred for three minutes before molding.

\subsection{Test and Characterization}

The specimens with molds were placed in a standard curing box, with a temperature of $20 \pm 2{ }^{\circ} \mathrm{C}$ and a relative humidity of more than $95 \%$ for $24 \pm 1 \mathrm{~h}$. Then, the specimens were released from the molds and were further cured until $7 \mathrm{~d}, 28 \mathrm{~d}, 90 \mathrm{~d}$.

The water retention test was conducted in accordance to DIN 18555-7 [32] using a filter-film allowing water to filter through, which is fixed on absorbent filter papers. The water retention rate was calculated based on the ratio of the mass of water absorbed by the filter papers. The consistence test for the workability evaluation was conducted in accordance to JGJ/T 70-2009 [33], with the depth of a standard cone sinking into the mortar mixture during the specified time.

According to JGJ/T 70-2009 [33], fresh mortar composites were cast into cubes molds, with a size of $70.7 \mathrm{~mm} \times 70.7 \mathrm{~mm} \times 70.7 \mathrm{~mm}$, for the compressive strength test and freeze resistance test. After immersing in water for two days, specimens that were cured for 28 days underwent 25 freeze-thaw cycles. For each test, six specimens were tested and the average values were reported.

Based on GB/T 17671-1999 [34], three specimens, with a size of $40 \mathrm{~mm} \times 40 \mathrm{~mm} \times 160 \mathrm{~mm}$, were prepared for the flexural strength test and the average values were reported. Using a universal testing machine, the load-displacement curve was obtained from the test.

The thermal conductivity of the material was evaluated through the dry density of the mortar [27]. The difference between the weight of the specimen under water-saturated and fully dried (dried at $105{ }^{\circ} \mathrm{C}$ to constant weight) conditions was used to calculate the water absorption of the hardened mortar. This is an intuitive approach to evaluate the porosity of mortars [28]. According to Archimedes principle, the dry density of specimens obtained from the broken sample after the flexural strength test can be determined by weighing. These were calculated using the following equation:

$$
\mathrm{A}=\frac{W_{s}-W_{0}}{W_{0}} \times 100 \%
$$




$$
\rho=\frac{W_{0}}{V}
$$

where, $\mathrm{A}$ is the mass water absorption $(\%), W_{S}$ is the weight of the specimens under watersaturated condition $(\mathrm{g}), W_{0}$ is the weight of the specimens under fully dried condition $(\mathrm{g})$, $V$ is the drainage volume of the specimens under water-saturated condition $\left(\mathrm{mm}^{3}\right), \rho$ is the dry density of the specimen $\left(\mathrm{kg} / \mathrm{m}^{3}\right)$.

An X-ray diffractometer (D max/RB Japan Rigaku Corporation) with a copper target $(\lambda=1.5418 \AA$ A $40 \mathrm{kV}, 30 \mathrm{~mA})$ was used. The sample to be tested was dried to constant weight, and tested after grinding. The scanning diffraction $2 \theta$ angle was $5^{\circ} \sim 80^{\circ}$, and the scanning speed was $2^{\circ} / \mathrm{min}$.

The mercury intrusion porosimetry was used to analyze the pore structure and pore size distribution of the test sample. The specimens were first broken into pieces, with a diameter of 2.5 to $5 \mathrm{~mm}$. Then these were soaked in acetone solution, and finally taken out and dried before the test (Poremaster GT-60; Quanta chrome, Houston, TX, USA)

\section{Results and Discussion}

\subsection{Effect of the Water-Binder Ratio on Mortar Properties}

The experimental mix ratio was calculated according to the weight. The ratio was, as follows: cement: fly ash: heavy calcium carbonate: quartz sand: EVSB: EVA: HPMC $(50,000 \mathrm{mPa} \cdot \mathrm{s})=72: 28: 12: 250: 30:$ 0.9:0.6. The water-binder ratio was $0.68,0.72,0.76,0.80$, and 0.84 .

Table 4 shows the performance of the mortar cured for 28 days. It can be seen that the dry density, the compressive strength, and flexural strength decreased as the $\mathrm{W} / \mathrm{B}$ ratio (the ratio of water to the total mass of fly ash and cement) increased. The reasons were because part of the water in the mortar participates in the hydration of the cementitious material, and the excess water evaporated, forming the porosity in the mortar. This can be verified through the increase in mass water absorption. When the $\mathrm{W} / \mathrm{B}$ ratio increased from 0.68 to 0.84 , the mass water absorption of the mortar increased by $8.3 \%$. Therefore, the $\mathrm{W} / \mathrm{B}$ ratio was considered suitable to be controlled at about 0.76 , and the responding consistency of the mortar is about $60 \mathrm{~mm}$ and the strength of mortar can meet the requirements with a small density.

Table 4. Influence of water-binder ratio on the properties of mortar.

\begin{tabular}{|c|c|c|c|c|c|}
\hline W/B & Consistency/mm & Dry Density/kg/m³ & $\begin{array}{c}\text { Mass Water } \\
\text { Absorption/\% }\end{array}$ & $\begin{array}{l}\text { Compressive } \\
\text { Strength/MPa }\end{array}$ & $\begin{array}{c}\text { Flexural } \\
\text { Strength/MPa }\end{array}$ \\
\hline 0.68 & 40 & 1340 & 11.3 & 18.0 & 3.3 \\
\hline 0.72 & 48 & 1270 & 15.4 & 12.4 & 2.4 \\
\hline 0.76 & 55 & 1190 & 15.9 & 9.0 & 2.0 \\
\hline 0.80 & 63 & 1170 & 16.3 & 6.7 & 1.6 \\
\hline 0.84 & 72 & 1130 & 19.6 & 3.3 & 1.2 \\
\hline
\end{tabular}

\subsection{Optimum for Lightweight Aggregate}

To ensure the rational selection of lightweight aggregates for the mortar, both EVSB and expanded perlite have the same particle size and a constant mix proportion. The effect of expanded perlite on the dry density and compressive strength of mortar was similar to EVSB. But at the same content, the compressive strength of the mortar, with expanded perlite as aggregate at 28 days, was lower than that of mortar with EVSB, as shown in Tables 5 and 6 . When the dosages were $20 \%, 22 \%, 24 \%, 26 \%$, and $28 \%$, the compressive strength of the mortar was reduced by $3.5 \mathrm{MPa}, 1.0 \mathrm{MPa}, 1.2 \mathrm{MPa}, 1.1 \mathrm{Mpa}$, and 1.7 $\mathrm{MPa}$ respectively. Mechanical properties and workability of the mortar were largely determined through the pore structure, which was most affected by the water requirement of the aggregate used. It has been reported that the incorporation of aggregates that are more porous leads to higher water absorption of the mortar [28]. Compared to the expanded perlite, EVSB has an almost smooth surface, as shown in Figure 3. Therefore, the water 
demand of the mortar with expanded perlite increased because of the high wettability. This reduced the workability of the mortar. Hence, EVSB is more suitable for the lightweight aggregate of plastering mortars.

Table 5. Influence of the dosage of expanded perlite on the properties of the mortar.

\begin{tabular}{cccc}
\hline Expanded Perlite/\% & Dry Density/kg/m & Mass Water Absorption/\% & Compressive Strength/MPa \\
\hline 20 & 1350 & 21.6 & 13.2 \\
22 & 1220 & 25.3 & 10.7 \\
24 & 1210 & 28.9 & 9.8 \\
26 & 1120 & 35.0 & 8.2 \\
28 & 1090 & 40.1 & 6.5 \\
\hline
\end{tabular}

Table 6. Influence of the amount of EVSB on the properties of mortar.

\begin{tabular}{cccc}
\hline EVSB/\% & Dry Density/kg/m & Mass Water Absorption/\% & Compressive Strength/MPa \\
\hline 20 & 1230 & 20.6 & 16.7 \\
22 & 1150 & 17.2 & 11.7 \\
24 & 1080 & 22.0 & 11.0 \\
26 & 1050 & 23.1 & 9.3 \\
28 & 990 & 24.4 & 8.2 \\
\hline
\end{tabular}

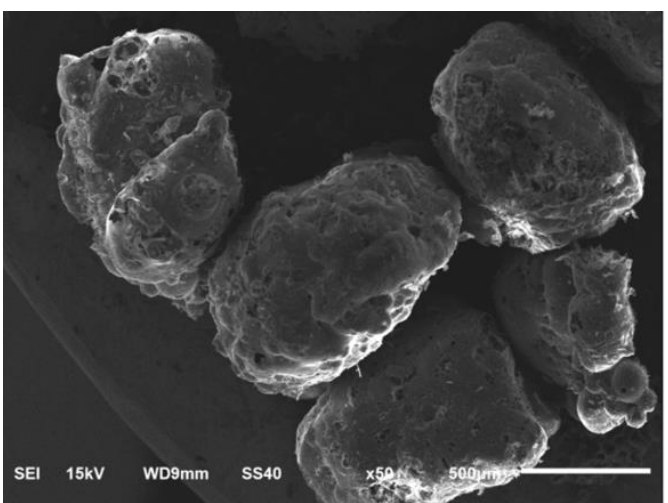

(a)

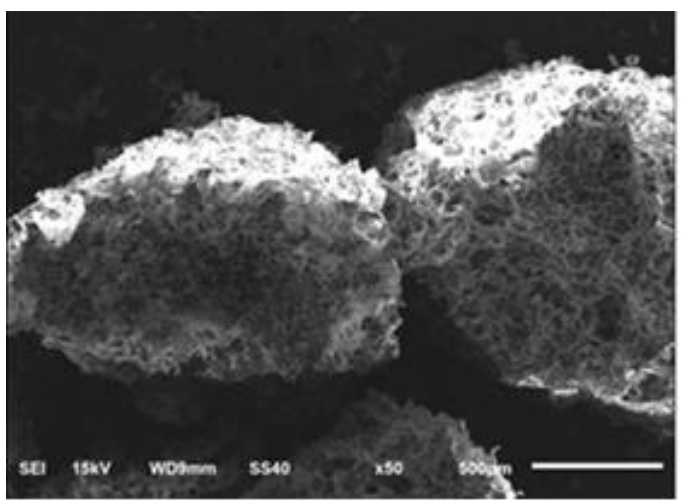

(b)

Figure 3. Comparison of scanning electron microscope images; (a) EVSB; (b) expanded perlite.

It can be observed from Table 6 that the amount of EVSB had a greater influence on the dry density of the mortar. As the ratio of EVSB to cement increased, the dry density of the mortar significantly decreased. This correspondingly improved the thermal insulation performance of the mortar.

The compressive strength was greatly affected by the content of EVSB. There are three reasons. First, the increase of EVSB content reduces the mass of cementitious material per unit volume due to the high volume fraction that stemmed from the low density. Second, EVSB was used as an aggregate. This can easily generate bubbles during the mixing process, which increases the porosity of the insulation mortar, and reduces the compactness. At the same time, this would also increase the water absorption. This was in agreement with previous observation reports [35-37]. Third, EVSB, as a lightweight aggregate, is not as mechanically strong as quartz sand. Hence, this would weaken the role of the skeleton when added. Liu et al. [38] agrees that EVSB forms a new skeleton to bear with the stress and dissipation of energy. Although this would reduce the elastic modulus of the plaster mortar, the plastic deformation ability of the plaster mortar improved.

Therefore, the dosage of EVSB was considered suitable to be controlled at approximately $24 \%$, in which the mortar has a small density, ensuring strength. 


\subsection{Factors That Influence the Performance of the Mortar}

\subsubsection{Fly Ash}

Replacing the cement with fly ash can reduce the use of cement, thereby reducing the costs. Studies have also shown that fly ash has a certain inhibitory effect on the drying shrinkage of mortar [37]. At the same time, the water requirement is reduced, which improves the workability of the mixture [39]. Figure 4 shows the relationship between the content of fly ash and the consistency of the mortar. It can be observed that fly ash can increase the consistency of the mortar through its approximately spherical glass microsphere particles. However, when the fly ash content was more than $40 \%$, the consistency began to decrease, due to the smaller particle size and larger specific surface area of the fly ash.

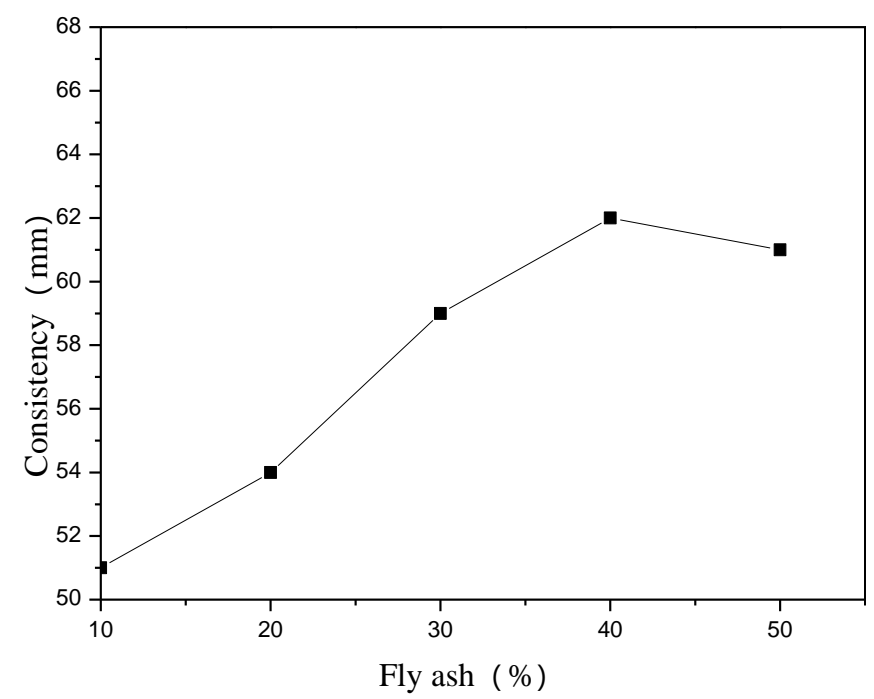

Figure 4. Effect of fly ash on the consistency of the mortar.

Figure 5a shows the relationship between the compressive strength of the mortar test block at 28 days and the content of fly ash. When the content of fly ash increased from $10 \%$ to $20 \%$, the strength of the mortar decreased the most, indicating that a small amount of fly ash had a great influence on the compressive strength of the mortar. The reason is that the hydration rate of fly ash is slow, and the total amount of hydration products in the system was small $[40,41]$. When the content of fly ash was increased, the amount of cement with higher brittleness was correspondingly reduced. This reduced the compressive strength-toflexural strength ratio of the mortar, and improved the toughness. Gao et al. [42] used the method of combining nanoindentation and scanning electron microscopy, and concluded that the addition of fly ash can reduce the elastic modulus of the microstructure of the mortar. This conclusion was also proven through macroscopic experiments. However, when the content of fly ash was too high, the negative effect of fly ash on the flexural strength of mortar increased, and the ratio of compressive strength-to-flexural strength ratio started to increase, as shown in Figure $5 b$. 


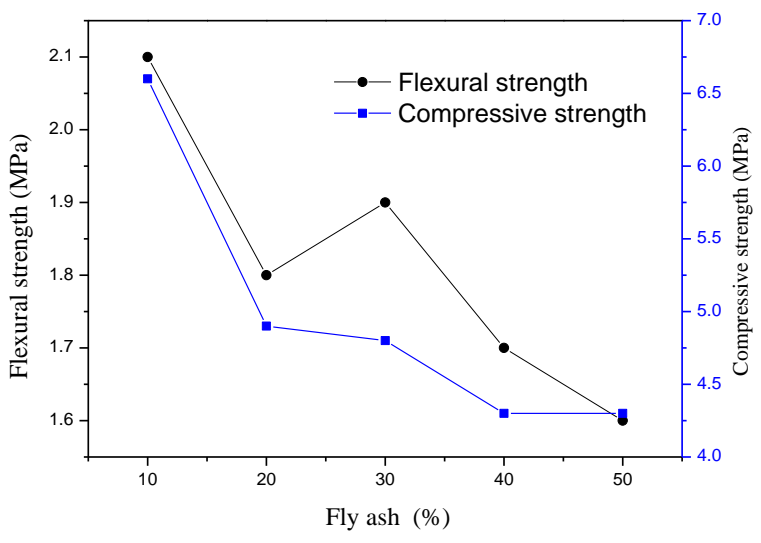

(a)

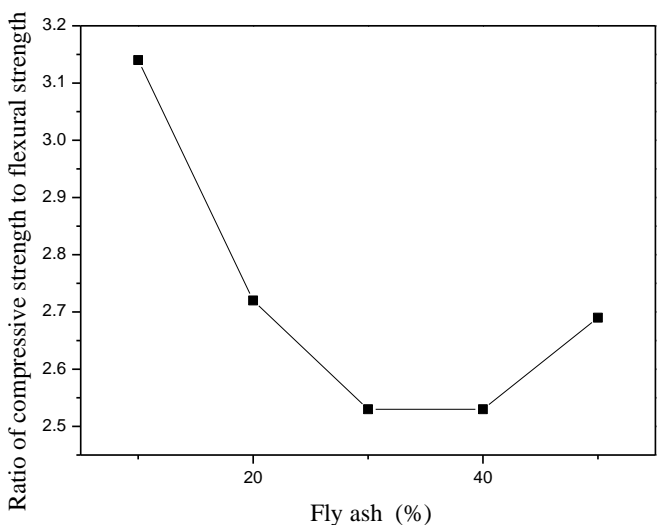

(b)

Figure 5. Influence of fly ash on the mechanical properties of mortars: (a) flexural strength and compressive strength, (b) ratio of compressive strength and flexural strength.

\subsubsection{EVA}

EVSB is a hollow low-density spherical particle with a vitrified surface, and provides high fluidity during the mixing process $[25,38,43]$. Hence, the particles can easily float in the mortar, which seriously affects the serviceability of the mortar. Therefore, it is necessary to add additives to improve the uniformity of the mortar. EVA is a high-molecular polymer, which has both hydrophilic and hydrophobic groups in the molecule. When this is dispersed in water, the hydrophobic group is adsorbed on the surface of the EVSB particles, and the hydrophilic group is bonded to the outside solution [44]. This has an agglomeration effect on aggregates and gelling materials, and enables aggregates to be easily wrapped by the slurry.

The results for the dry density, compressive strength, and flexural strength of the mortar samples that contained $0 \%, 1 \%, 2 \%, 3 \%, 4 \%$, and 5\% EVA are shown in Figures 6 and 7. It can be seen that the dry density of the mortar with 1\% EVA content was the largest. Compared to the mortar with $0 \%$ content, EVA can induce the aggregate to be evenly distributed inside the mortar, instead of floating on the surface. In this manner, packing is denser. However, as the EVA content continued to increase, the dry density of the mortar decreased, and the dry density of the mortar with an EVA content of $5 \%$ was similar to the control $(0 \%)$. This was due to the air-entraining effect of the EVA, which caused an increase in porosity inside the mortar.

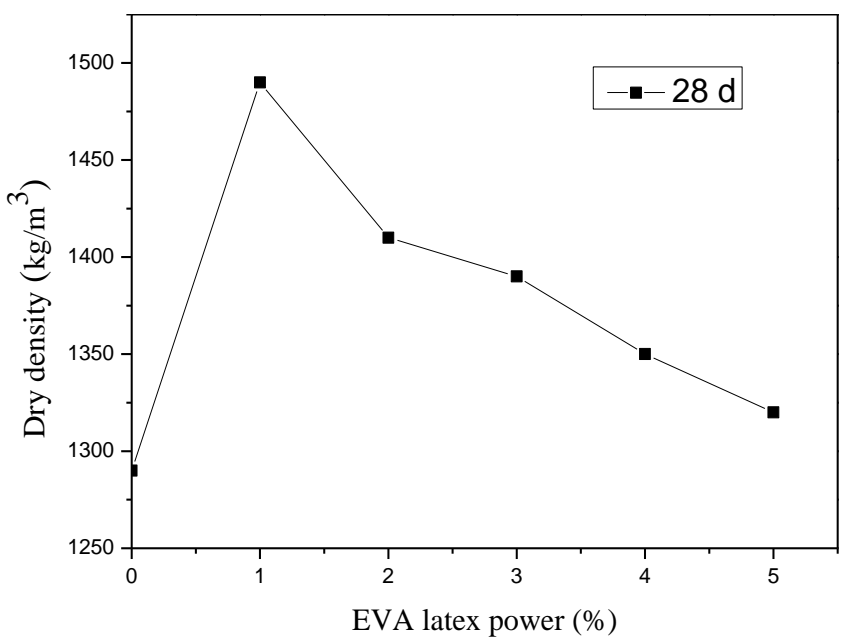

Figure 6. Effect of EVA on the dry density of mortar. 


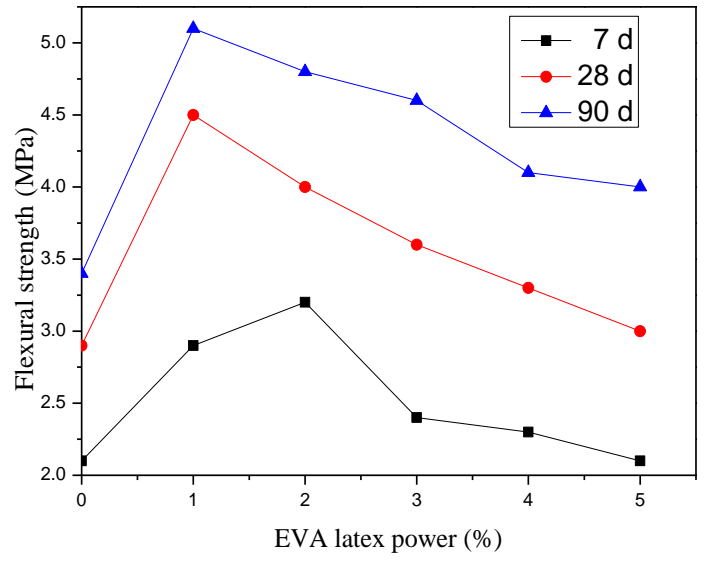

(a)

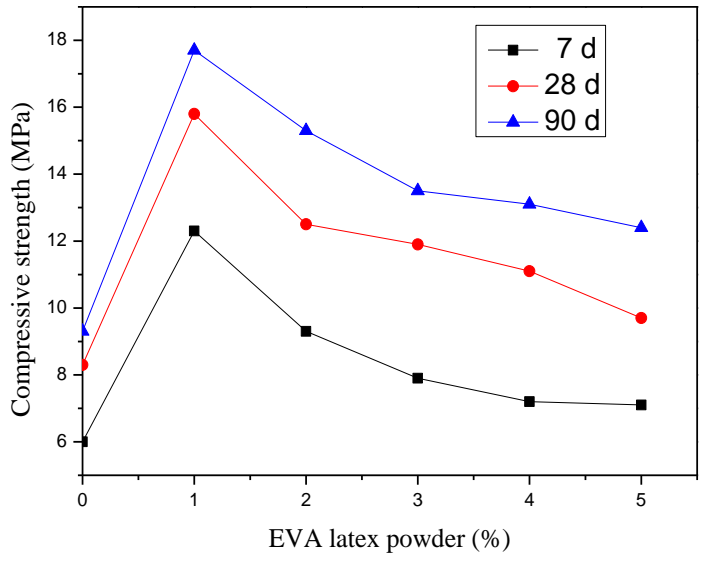

(b)

Figure 7. Influence of EVA on the mechanical properties of mortars: (a) flexural strength, (b) compressive strength.

It can be seen from Figure 7 that for the different age groups, the effect of EVA content on the strength of the mortar was roughly the same. The addition of a small amount of EVA can increase the flexural and compressive strength of the mortar. For the different age groups, the compressive strength of the mortar was highest when the EVA content was $1 \%$, which corresponds to the effect of the EVA content on the dry density in Figure 6. The dry density of the mortar with 1\% EVA content was the largest, and the test block was the most compact. Hence, the strength was also the highest. A small amount of EVA forms a polymer film in the pores. This polymer film has toughness and elasticity. When the mortar is subjected to external forces, the interwoven polymer film would relieve the internal stress of the mortar, thereby reducing the strain. Nazia Tarannum [45] agrees that the polymer has a function similar to the mobile joint between particles of cement mortars, which can reduce the stress and improve the resistance to deformation. Figure 8 shows that compared with the control mortar without EVA, the micro cracks of mortars with $2 \%$ EVA content significantly decreased. The polymer membrane filled the pores of the hydration product, making the structure more compact, but there were still some large pores.

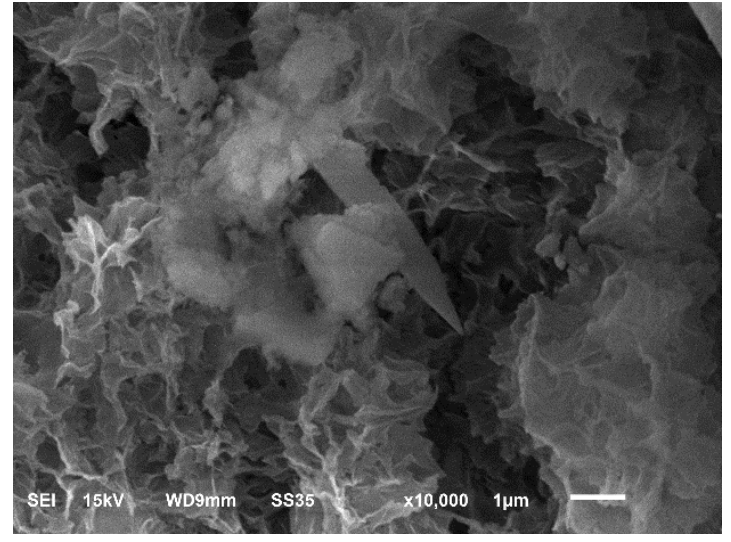

(a)

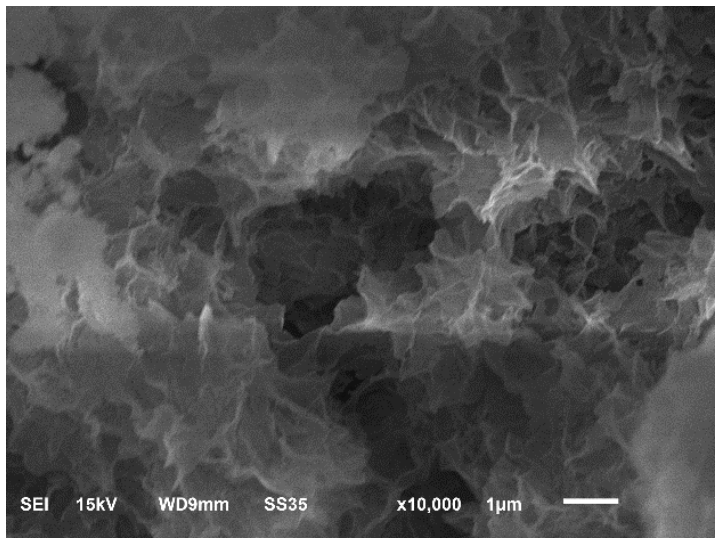

(b)

Figure 8. The scanning electron micrograph of the mortar: (a) the control, (b) the mortar with $2 \%$ content of EVA.

For the increase in content of EVA, the air-entraining effect of the EVA is reflected, and the porosity of the mortar is increased. This effect is much greater than the cohesion of the EVA, causing the strength to decrease. The reduction in the density of the thermal insulation mortar, allowed this to achieve the thermal insulation effect, and have better 
mechanical properties. For the thermal insulation mortar prepared in this experiment, it was suitable to use the EVA with a content of $2 \%$.

\subsubsection{HPMC}

In view of the hydrophobicity and low density characteristics of EVSB particles, HPMC has the same effect as EVA, which can prevent the separation and bleeding of mortar during the mixing process, and has good effects of water retention and thickening [46-48].

HPMC is a non-ionic water-soluble organic polymer with hydrophilic hydroxyl and ether bonds in its molecular structure. The water molecules in mortar combine with the oxygen atoms on the hydroxyl group and the ether bond to form a hydrogen bond, and HPMC forms a gel with water, which makes the free water lose its fluidity [46]. Therefore, HPMC has a water retention effect. Figure 9a shows that when the HPMC $(50,000 \mathrm{mPa} \cdot \mathrm{s})$ content is from $0 \%$ to $0.3 \%$, the water retention rate of the mortar increased from $83.0 \%$ to $91.0 \%$, and when the HPMC content was more than $0.6 \%$, the water retention rate gently increased. The influence law of HPMC on mortar consistency in Figure $9 \mathrm{~b}$ shows that regardless of the amount of the HPMC, this would have a great improvement effect on mortar consistency, and this has the best effect when the content is $0.1 \%$. By comparing the effects of HPMC with the three kinds of viscosity, it can be found that water retention increases with the increase in HPMC viscosity, and HPMC, with a viscosity of 100,000 mPa.s has the most obvious effect of increasing consistency. Paweł Pichniarczyk [46] agrees that low viscosity cannot provide good performance.

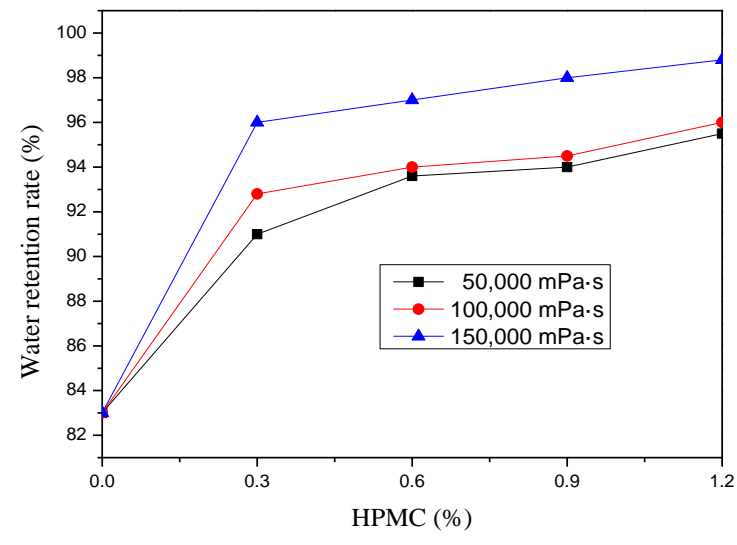

(a)

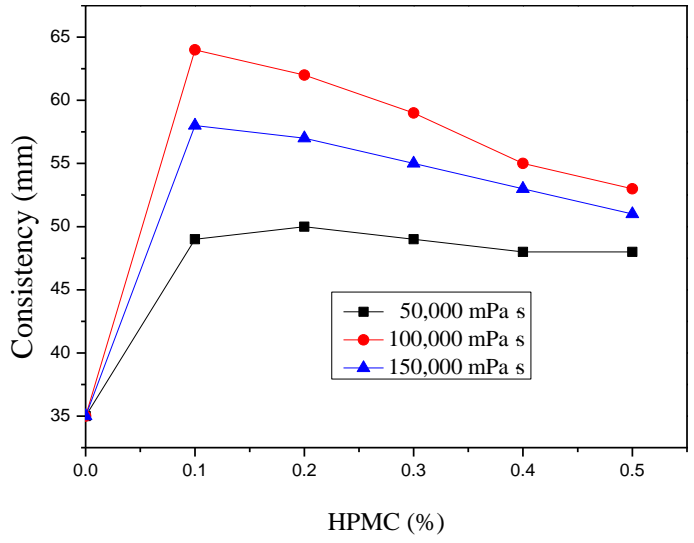

(b)

Figure 9. Influence of hydroxypropyl methylcellulose (HPMC) on the performance of fresh mortar: (a) Water retention rate, (b) consistency.

Figure 10a,b shows the relationship between the mechanical strength of the mortar at 28 days, and the different contents of HPMC with two different viscosities. Regardless of the content of HPMC, the mechanical strength of the mortar would significantly decrease. This is consistent with the results reported by many studies [10,49]. When the HPMC content was more than $0.3 \%$, the downward trend of flexural and compressive strength tends to be gentle. However, at the same content, the mechanical strength of mortars mixed with HPMC with a viscosity of $100,000 \mathrm{mPa} \cdot \mathrm{s}$ was higher, when compared to that with a viscosity of $150,000 \mathrm{mPa} \cdot \mathrm{s}$. The crack resistance of the mortar was evaluated using the compressive strength-flexural strength ratio. As shown in Figure 10c, as the content of HPMC increased, the ratio decreased and this improved the crack resistance. When the curves for the HPMC of both viscosities were at the $0.3 \%$ position, the slope of the line decreased, indicating that the degree of improvement in crack resistance decreased. 


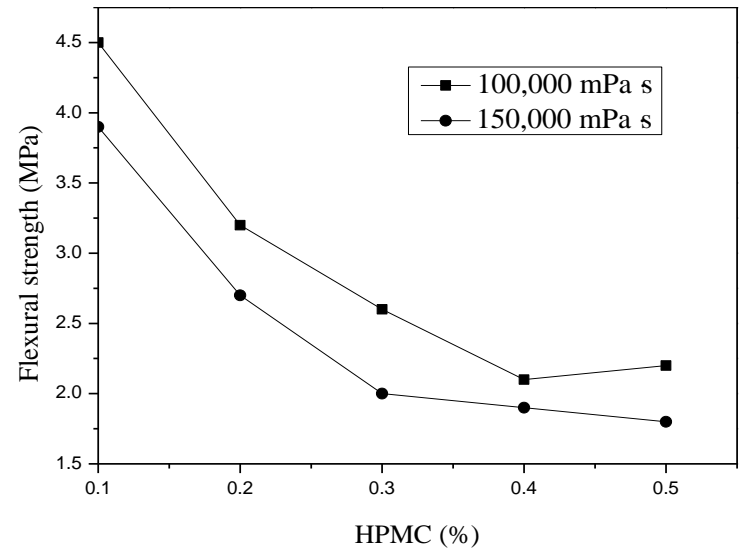

(a)

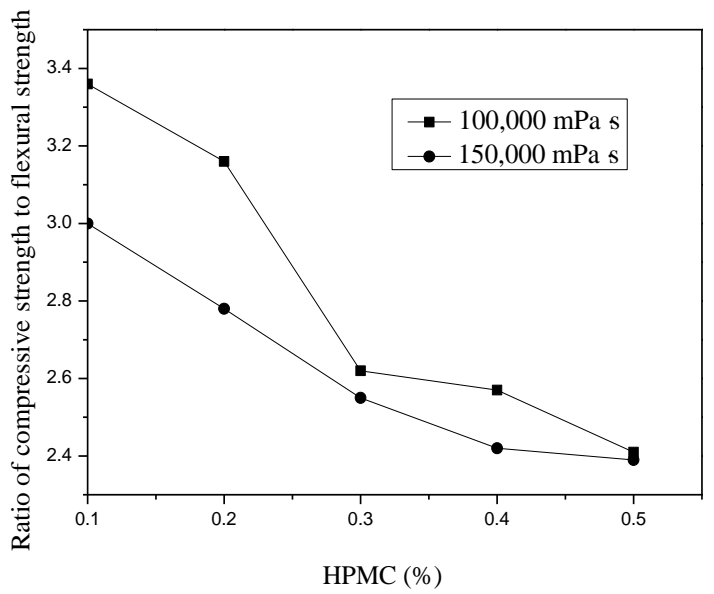

(c)

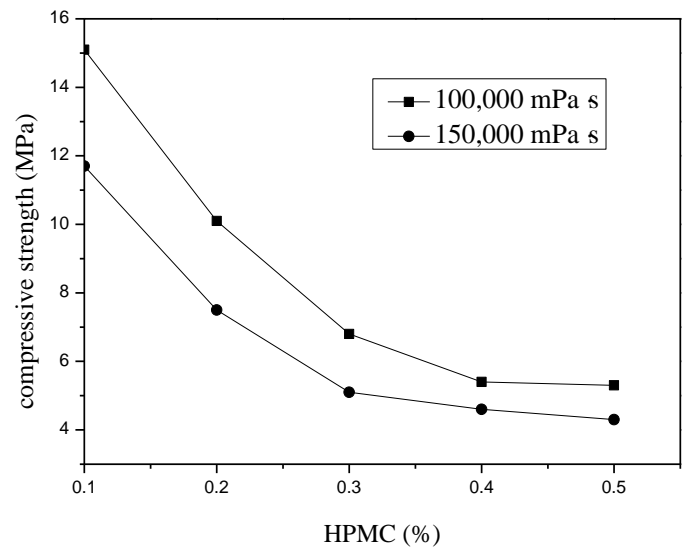

(b)

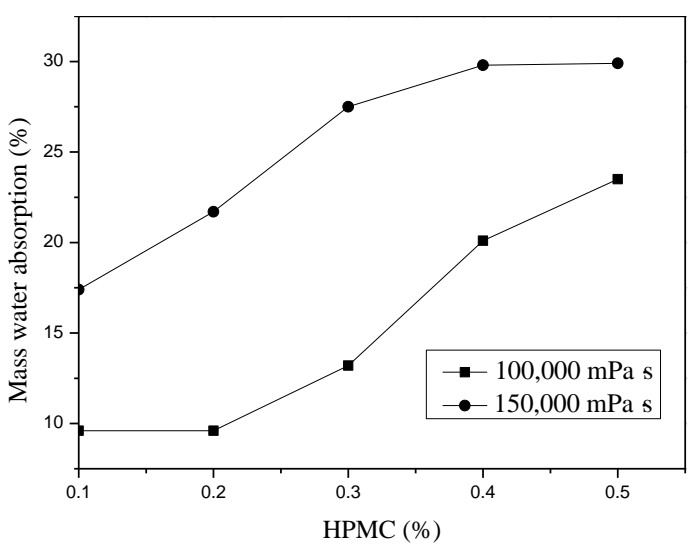

(d)

Figure 10. Effect of HPMC on the properties of the mortar. (a) Flexural strength; (b) compressive strength; (c) the compressive strength-to-flexural strength ratio; (d) water absorption.

HPMC reduces the mechanical strength of cement mortar, which was mainly because HPMC introduces gas into the slurry. These gases form pores after the mortar hardens, which reduces the compactness of the mortar structure and thereby reduces the mechanical strength. The increase in water absorption in Figure $10 \mathrm{~d}$ also proves the increase in pores inside the mortar. Chen Shi [49] agrees that although the introduction of pores reduces the strength, the excellent water retention capacity can improve the stability of ettringaite in the late age, thereby ensuring the development of late strength. Figure 11 shows the relationship between the pore size distribution of thermal insulation mortar and the viscosity of HPMC. It can be intuitively observed that the total pore volume of the mortar mixed with HPMC with a viscosity of $150,000 \mathrm{mPa} \cdot \mathrm{s}$ was greater than the mortar mixed with HPMC with a viscosity of $100,000 \mathrm{mPa} \cdot \mathrm{s}$. The pore size of the former was relatively large, while the pore size of the latter was mainly distributed below $0.5 \mu \mathrm{m}$, and the pore size distribution was more uniform. This further shows that the greater the viscosity of $\mathrm{HPMC}$, the more obvious the air-entraining effect. 


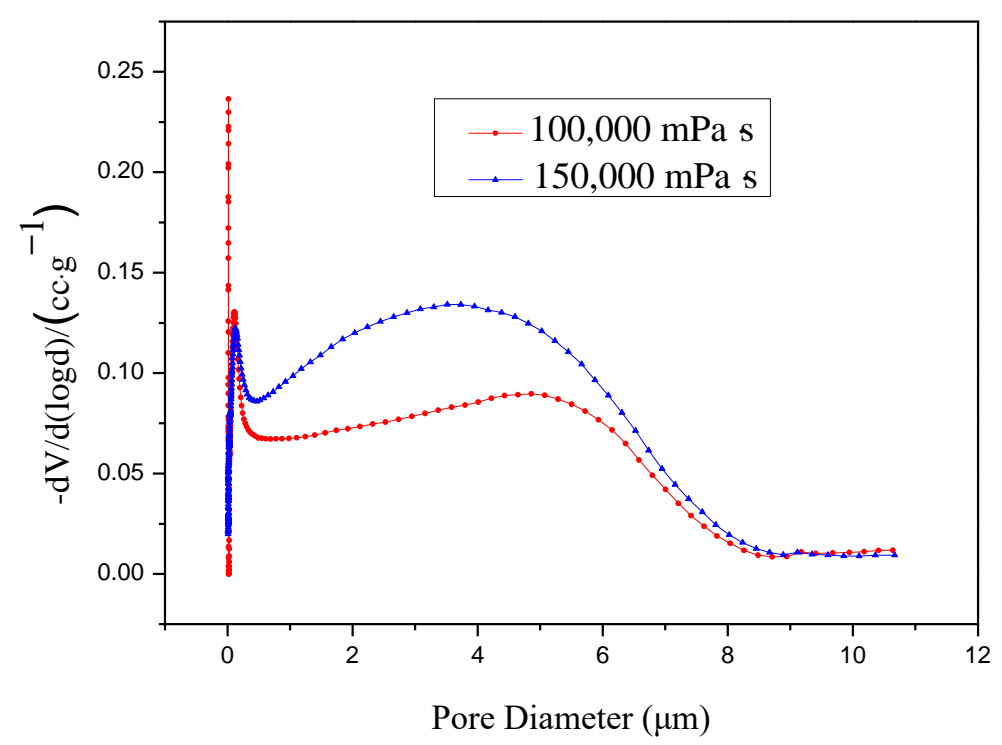

Figure 11. Pore structure of the mortar with $0.3 \%$ content HPMC.

In order to reduce the influence of air entrainment on mechanical strength, HPMC with a viscosity of $100,000 \mathrm{mPa} \cdot \mathrm{s}$ was selected, and the modified mortar with different dosages was used for 25 freeze-thaw cycles. The relationship between mass and strength loss rate and HPMC content is shown in Figure 12a,b, respectively. When the amount of HPMC was less than $0.4 \%$, the greater the dosage, the lower the quality and strength loss of the mortar after 25 freeze-thaw cycles. The water absorption of the mortar can roughly reflect its air content. HPMC, as an air-entraining agent, improves the water absorption of mortars after being mixed. Figure $12 \mathrm{c}, \mathrm{d}$ show the changes of the mass and strength loss with the water absorption rate after 25 freeze-thaw cycles on the mortar, respectively. The greater the water absorption rate of the mortar, the lower the loss rate of quality and strength. However, when the water absorption rate was greater than $20 \%$, the loss rate increased.

This phenomenon can be explained by the hydrostatic pressure theory [50]. When the water in the pores of the mortar freezes, the volume would expand by $9 \%$, causing the unfrozen solution in the pores to migrate outward from the frozen area. In this process, the migration of water overcomes the viscous resistance, and results in the formation of hydrostatic pressure, thereby damaging the internal structure of the mortar. The effect of the pore structure on the antifreeze performance was mainly, as follows: Pores with larger pore diameters would not adversely affect the frost resistance of the mortar; the medium pore diameter capillary holes and micro cracks in the matrix pores are the main factors that cause adverse effects on the antifreeze performance, while gel pores with the smallest pore size have little adverse effect on the antifreeze performance [51]. Incorporating HPMC into the slurry can introduce uniformly distributed and stably closed pores that would not adversely affect the frost resistance. These pores reduce the spacing of the internal pores of the mortar, which in turn, reduce the migration path of water in the pores during the freezing process, causing a good buffering effect on the expansion pressure caused by the freezing of water in the pores. However, when the water absorption rate was more than $20 \%$, that is, the air content was too large, the pore spacing would be too small, resulting in the decrease in strength of the pore structure [52], and the decrease in ability to resist freezing expansion pressure. 


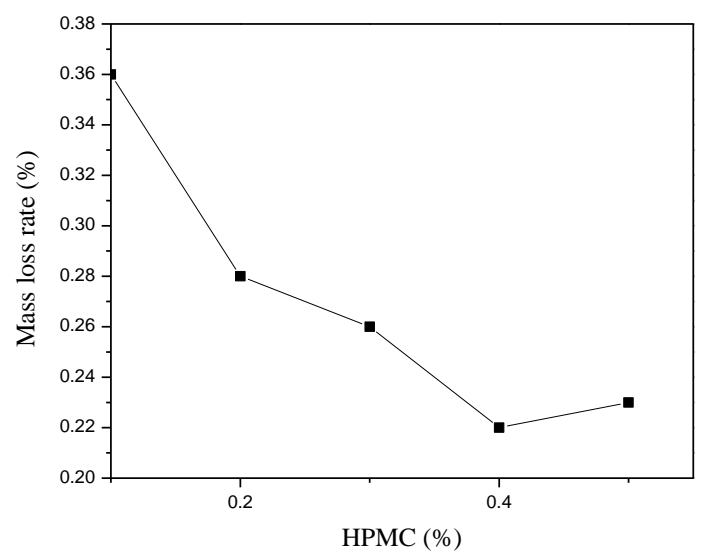

(a)

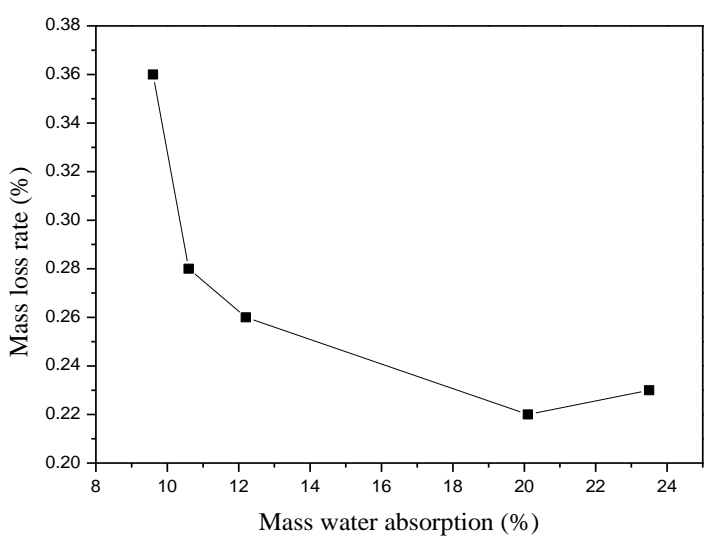

(c)

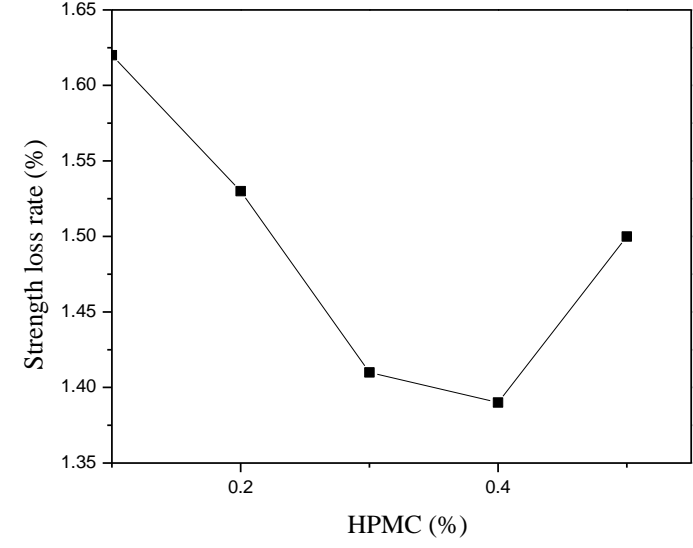

(b)

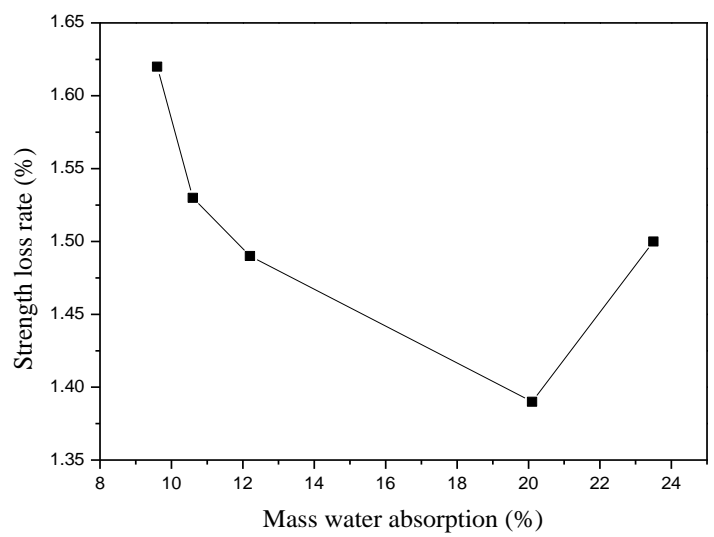

(d)

Figure 12. The regular pattern of frost resistance. (a) mass loss rate; (b) strength loss rate; (c) water absorption-mass loss; (d) water absorption-strength loss.

\subsubsection{Fibers}

3-mm and 6-mm polypropylene (PP) fibers, with contents of $0,0.2 \%, 0.4 \%, 0.6 \%$ and $0.8 \%$, were used to investigate the effect of fiber on the crack resistance of the mortar. Figure 13 shows the relationship between the polypropylene fiber content and the compressive strength-to-flexural strength ratio of the mortar at 28 days. It can be seen that a small content of fiber in the mortar can significantly reduce this ratio, and that the fiber modification effect was the best at $0.2 \%$ content. When the content ranged within $0.2 \%-$ $0.6 \%$, the compressive strength-to-flexural strength ratio of mortar mixed with two lengths of fiber was much lower than that of mortar without fiber, and in this range, the effect of the 3-mm fiber was better than 6-mm fiber. As the fiber content continued to increase, the compressive strength-to-flexural strength ratio also continued to increase. This was because the excess fiber reduced the workability of the mortar. In order to characterize the toughness of the mortar in a better manner, a load-displacement test was carried out. 


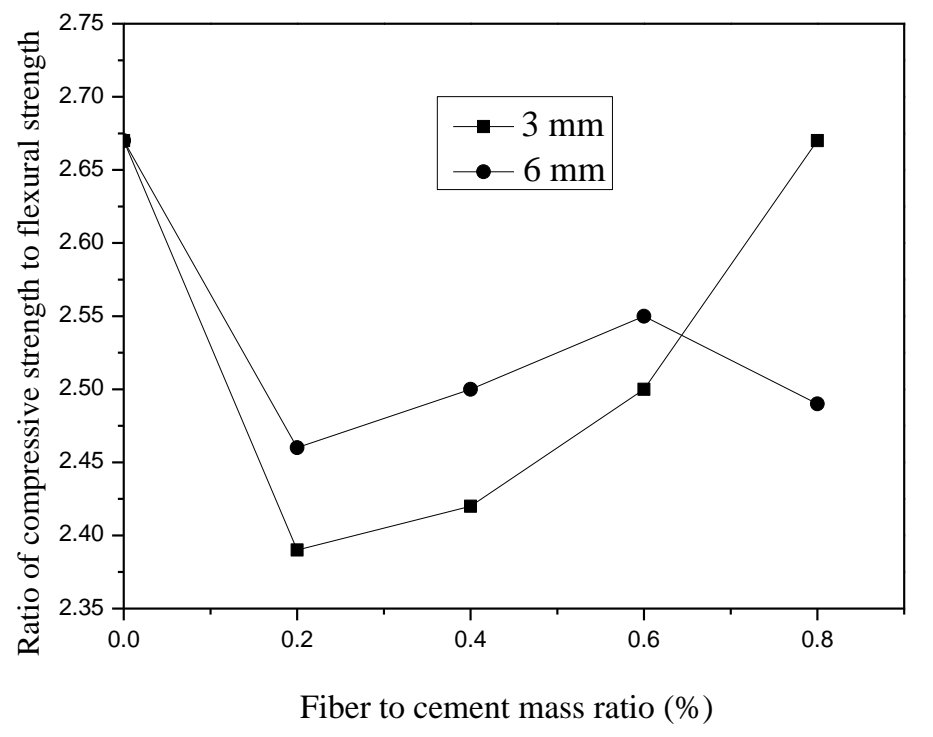

Figure 13. Effect of fiber on the compressive strength-to-flexural strength ratio of mortars.

Although the curve with the lowest slope in Figure $14 \mathrm{~b}$ was the $0.2 \%$ fiber content, the difference among the slopes of the five curves was small. The comparison with Figure 14a shows that the influence of the $6-\mathrm{mm}$ fiber on the elastic modulus of the mortar was less than the 3-mm fiber. Previous studies [53-55] have also shown that fibers do not significantly change the elastic modulus and compressive strength of the specimen. The conclusions obtained in Figure 14 were roughly consistent with those obtained in Figure 13. When the polypropylene fiber content was $0.2 \%$, the effect of improving the toughness was the best. Danar Altalabani et al. [54] concluded that fibers can enhance the ductility of cement-based materials, but considers that only the use of macroscopic and hybrid fibers can significantly improve the toughness.

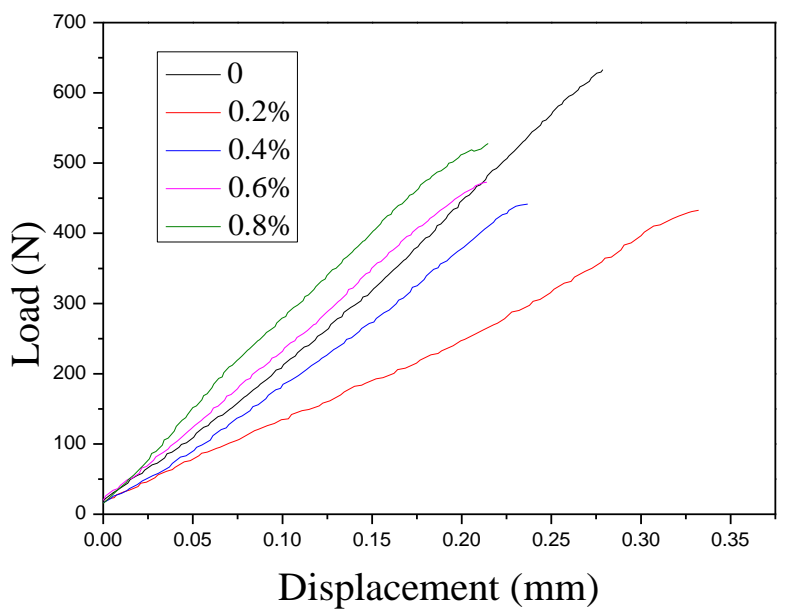

(a)

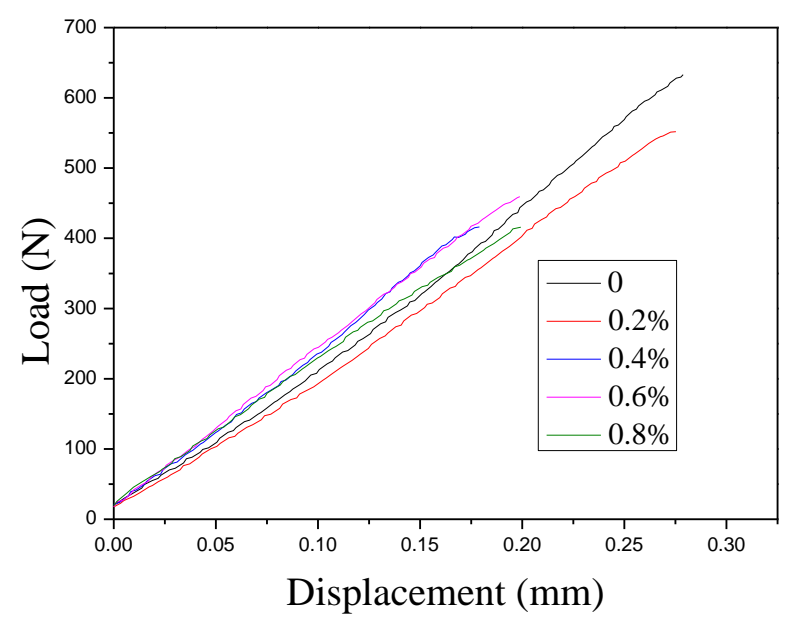

(b)

Figure 14. Load-displacement curve of the mortar: (a) 3-mm PP fiber, (b) 6-mm PP fiber.

\section{Conclusions}

The research was dedicated to the development of a novel plastering mortar for $\mathrm{AAB}$ walls, which were characterized with a decrease in density and heat conductivity, and an increase in toughness and durability, when compared with presently used products. The following conclusions are drawn from this study: 
(1) Based on the test results, the best mix proportion was drawn, and the ratio was, as follows: cement: fly ash: water: heavy calcium carbonate: quartz sand:EVSB:EVA:HPMC $(100,000 \mathrm{mPa} \cdot \mathrm{s})$ :fiber $=70: 30: 76: 12: 250: 24: 2: 0.3: 0.2$.

(2) In order to achieve the purpose of reducing the heat transfer coefficient, the effects of two types of lightweight fillers on the performance of mortars were evaluated. Contrary to the expanded perlite, the hydrophobicity of EVSB particles would reduce the water absorption of the mortar, thereby increasing the mechanical strength of the mortar.

(3) The incorporation of fly ash can improve the workability of the freshly mixed mortar, and reduce the mechanical strength of the mortar. When the fly ash content was less than $40 \%$, increasing the content can improve the crack resistance of the mortar.

(4) $2 \%$ EVA can reduce the micro cracks and fill the pores, improving mortar compactness. EVA enhances the cohesion and air-entraining properties of the mortar, and jointly affects the dry density of the mortar.

(5) In terms of workability, compressive strength, flexural strength, mass water absorption, and pore structure, the optimum dosage of HPMC $(100,000 \mathrm{mPa} \cdot \mathrm{s})$ was $0.3 \%$. After 25 freeze-thaw cycle tests, the mass loss was $0.26 \%$, and the strength loss was $1.41 \%$.

(6) The 3-mm fiber had a better effect in improving the crack resistance of the mortar, when compared to the 6-mm fiber. When the content was $0.2 \%$, this had the best toughness improvement effect, and exhibited greater deformation under the same load.

Author Contributions: Conceptualization, L.X.; tests and data interpretation, T.F., X.S., P.Z., and J.H.; writing - original draft preparation, T.F.; review and editing, T.F. and L.X.; All authors have read and agreed to the published version of the manuscript.

Funding: This research was funded by the National Key Research \& Development Program of China (No. 2018YFD1101005).

Data Availability Statement: The data used to support the findings of this study are included within the article.

Acknowledgments: The authors would like to acknowledge the assistance from Zhidong He, Ruijie Jiang, Yang Wang, Jiajia Cheng, and Zemeng Guo from Nanjing Tech University.

Conflicts of Interest: The authors declare no conflict of interest.

\section{References}

1. Qu, X.L.; Zhao, X.G. Previous and present investigations on the components, microstructure and main properties of autoclaved aerated concrete-A review. Constr. Build. Mater. 2017, 135, 505-516. [CrossRef]

2. Zhou, C.Y.; Wei, J.X.; Yu, Q.J.; Yin, S.H.; Zhuang, Z.H.; Lei, Z.H. Water absorption characteristics of autoclaved aerated concrete. J. Wuhan Univ. Technol. 2007, 22-26. [CrossRef]

3. Guo, X.L.; Zhang, T.J. Utilization of municipal solid waste incineration fly ash to produce autoclaved and modified wall blocks. J. Clean. Prod. 2020, 252, 119759. [CrossRef]

4. Kunchariyakun, K.; Asavapisit, S.; Sombatsompop, K. Properties of autoclaved aerated concrete incorporating rice husk ash as partial replacement for fine aggregate. Cem. Concr. Compos. 2015, 55, 11-16. [CrossRef]

5. Tao, Y.S.; Wang, B.Z. Production of Autoclaved Aerated Concrete Blocks; China Building Materials Press: Beijing, China, 2018.

6. Wang, Y.L.; Zhou, M.K.; Shan, J.h.; Xu, F.; Yang, Y.H. Influences of carboxyl methyl cellulose on performances of mortar. J. Wuhan Univ. Technol. Mat. Sci. Edit. 2007, 22, 108-111. [CrossRef]

7. Loganina, V.; Frolov, M.; Fediuk, R. Developed Heat-insulating Dry Mortar Mixes for the Finishing of Aerated Concrete Walls. Mag. Concr. Res. 2020, 1900446. [CrossRef]

8. Mirza, J.; Mirza, M.S.; Lapointe, R. Laboratory and field performance of polymer-modified cement-based repair mortars in cold climates. Constr. Build. Mater. 2002, 16, 365-374. [CrossRef]

9. Raj, A.; Borsaikia, A.C.; Dixit, U.S. Bond strength of Autoclaved Aerated Concrete (AAC) masonry using various joint materials. J. Build. Eng. 2020, 28, 101039. [CrossRef]

10. Chen, S.; Xu, G.; Liu, D.M.; Peng, Y.Z.; Liu, Y.G. Study on mechanical properties of decorative mortar for autoclaved aerated concrete block. Concrete 2018, 98-101. [CrossRef] 
11. Zhuang, Z.H.; Huang, Q.L.; Wang, Y.; Ma, Z.X. Research on the Improvement Technology of Bonding Performance of Plaster Mortar and Aerated Concrete Wall. China Concr. Cem. Prod. 2020, 71-74. [CrossRef]

12. Li, Y.; He, H. Research progress of polymer-modified cement mortar. J. Funct. Mater. 2016, 47, 7038-7045. [CrossRef]

13. Wang, R.; Wang, P.M.; Peng, Y. Comparison of Three Characterization Methods for Flexibility of SBR Latex-Modified Cement Mortar. J. Build. Mater. 2010, 13, 390-394. [CrossRef]

14. Wang, R.; Wang, P.M.; Li, X.G. Physical and mechanical properties of styrene-butadiene rubber emulsion modified cement mortars. Cem. Concr. Res. 2005, 35, 900-906. [CrossRef]

15. Lezgy-Nazargah, M.; Vidal, P.; Polit, O. A 1D nonlinear finite element model for analysis of composite foam-insulated concrete sandwich panels. Compos. Struct. 2019, 210, 663-675. [CrossRef]

16. Kang, J.S. Composite and non-composite behaviors of foam-insulated concrete sandwich panels. Compos. Part B Eng. 2015, 68, 153-161. [CrossRef]

17. Cheng, J.; Xu, X.H.; Zhang, X.Y.; Dou, P.; Shi, Y.H.; Zhang, Q.; Huang, Z.L. Numerical simulation of the weathering performance of an exterior wall external insulation system under heating-cooling cycles. Chin. J. Eng. 2018, 40, 754-759.

18. Li, F.L.; Chen, G.L.; Zhang, Y.Y.; Hao, Y.C.; Si, Z.K. Fundamental Properties and Thermal Transferability of Masonry Built by Autoclaved Aerated Concrete Self-Insulation Blocks. Materials 2020, 13, 1680. [CrossRef]

19. Gorshkov, A.S.; Vatin, N.I. The innovative technology for erection of wall constructions of autoclaved aerated concrete blocks on polyurethane adhesive. Constr. Unique Build. Struct. 2013, 8, 20-28.

20. Gao, J.P.; Lei, L.; Wu, Y.B.; Xiong, Y.J. Experiment and analysis on load bearing of thermal insulation composite wall. J. Hunan Inst. Eng. 2014, 4, 87-90. [CrossRef]

21. Zhang, T.T.; Tan, Y.F.; Li, Y.Z. Thermal Bridge Effect of Aerated Concrete Wall and Its Partial Insulation. J. Hunan Univ. Nat. Sci. Ed. 2015, 42, 114-120. [CrossRef]

22. Liu, X.J.; Tang, T. Research on Basic Thermal Conductivity of Insulation Mortar and Ordinary Mortar. J. Hunan Inst. Eng. Nat. Sci. Ed. 2013, 23, 84-86. [CrossRef]

23. Maia, J.; Ramos, N.M.M.; De Freitas, V.P.; Sousa, A. Laboratory Tests and Potential of Thermal Insulation Plasters. Energy Procedia 2015, 78, 2724-2729. [CrossRef]

24. Leong, G.W.; Mo, K.H.; Loh, Z.P.; Ibrahim, Z. Mechanical properties and drying shrinkage of lightweight cementitious composite incorporating perlite microspheres and polypropylene fibers. Constr. Build. Mater. 2020, 246, 118410. [CrossRef]

25. Fang, P.; Mukhopadhyaya, P.; Kumaran, K.; Shi, C.J. Sorption and Thermal Properties of Insulating Mortars with Expanded and Vitrified Small Ball. J. Test. Eval. 2011, 39, 210-218. [CrossRef]

26. Kim, H.K.; Jeon, J.H.; Lee, H.K. Workability, and mechanical, acoustic and thermal properties of lightweight aggregate concrete with a high volume of entrained air. Constr. Build. Mater. 2012, 29, 193-200. [CrossRef]

27. Abd Elrahman, M.; El Madawy, M.E.; Chung, S.Y.; Majer, S.; Youssf, O.; Sikora, P. An Investigation of the Mechanical and Physical Characteristics of Cement Paste Incorporating Different Air Entraining Agents using X-ray Micro-Computed Tomography. Crystals 2020, 10, 23. [CrossRef]

28. Koksal, F.; Gencel, O.; Kaya, M. Combined effect of silica fume and expanded vermiculite on properties of lightweight mortars at ambient and elevated temperatures. Constr. Build. Mater. 2015, 88, 175-187. [CrossRef]

29. Zhou, Y.; Wang, S.X.; Liu, Z.H.; Ma, J.P.; Wang, T. Simulation Study On Composite Phase Change Thermal Insulationwalls in Solar Greenhouse Based on ANSYS. Acta Energiae Sin. 2020, 41, 113-122.

30. Zhang, J.; Chen, B.; Yu, F. Preparation of EPS-Based Thermal Insulation Mortar with Improved Thermal and Mechanical Properties. J. Mater. Civ. Eng. 2019, 31, 04019183. [CrossRef]

31. Arslan, M.E.; Celebi, E. An experimental study on cyclic behavior of aerated concrete block masonry walls retrofitted with different methods. Constr. Build. Mater. 2019, 200, 226-239. [CrossRef]

32. German Institute for Standardization. Testing of Mortars Containing Mineral Binders_Part 7: Determination of Water Retention of Freshly Mixed Mortar by the Filter Plate Method; DIN 18555-7; Deutsches Institut für Normung: Berlin, Germany, 2000.

33. China National Standards. Standard for Test Method of Basic Properties of Construction Mortar; JGJ/T70-2009; Ministry of Housing and Urban-Rural Development: Beijing, China, 2009.

34. China National Standards. Method of Testing Cements—Determination of Strength; GB/T 17671-1999; General Administration of Quality Supervision, Inspection and Quarantine: Beijing, China, 1999.

35. Su, Z.H.; Guo, L.; Zhang, Z.H.; Duan, P. Influence of different fibers on properties of thermal insulation composites based on geopolymer blended with glazed hollow bead. Constr. Build. Mater. 2019, 203, 525-540. [CrossRef]

36. Zhang, Y.; Ma, G.; Wang, Z.F.; Niu, Z.; Liu, Y.Z.; Li, Z. Shear behavior of reinforced glazed hollow bead insulation concrete beams. Constr. Build. Mater. 2018, 174, 81-95. [CrossRef]

37. Wang, W.J.; Liu, Y.Z.; Li, Z.; Zhao, L.; Chen, Y.F. Calculation on effective thermal conductivity of recycled aggregate thermal insulation concrete with added glazed hollow beads. Mater. Test. 2017, 59, 202-209. [CrossRef]

38. Liu, Y.Z.; Wang, W.J.; Zhang, Y.; Li, Z. Mechanical properties of thermal insulation concrete with a high volume of glazed hollow beads. Mag. Concr. Res. 2015, 67, 693-706. [CrossRef]

39. Chindaprasirt, P.; Buapa, N.; Cao, H.T. Mixed cement containing fly ash for masonry and plastering work. Constr. Build. Mater. 2005, 19, 612-618. [CrossRef] 
40. Li, D.X.; Shen, J.L.; Chen, Y.M.; Cheng, L.; Wu, X.Q. Study of properties on fly ash-slag complex cement. Cem. Concr. Res. 2000, 30, 1381-1387. [CrossRef]

41. Alaka, H.A.; Oyedele, L.O. High volume fly ash concrete: The practical impact of using superabundant dose of high range water reducer. J. Build. Eng. 2016, 8, 81-90. [CrossRef]

42. Gao, Y.Y.; Hu, C.L.; Zhang, Y.M.; Li, Z.J.; Pan, J.L. Investigation on microstructure and microstructural elastic properties of mortar incorporating fly ash. Cem. Concr. Compos. 2018, 86, 315-321. [CrossRef]

43. Fang, P.; Wu, Y.; Gong, G.C. Study on the Microstructure of Expanded and Vitrified Small Balls and Its Sorption Performance. Mater. Rev. 2009, 23, 112-114.

44. Baueregger, S.; Perello, M.; Plank, J. Role of PVOH and kaolin on colloidal stability of liquid and powder EVA and SB latexes in cement pore solution. Colloid Surf. A Physicochem. Eng. Asp. 2013, 434, 145-153. [CrossRef]

45. Tarannum, N.; Pooja, K.; Khan, R. Preparation and applications of hydrophobic multicomponent based redispersible polymer powder: A review. Constr. Build. Mater. 2020, 247, 118579. [CrossRef]

46. Pichniarczyk, P.; Niziurska, M. Properties of ceramic tile adhesives modified by different viscosity hydroxypropyl methylcellulose. Constr. Build. Mater. 2015, 77, 227-232. [CrossRef]

47. Chen, S.F.; He, R.; Li, Y.P.; Xing, M.L.; Cong, P.L. Influence of thickeners on cement paste structure and performance of engineered cementitious composites. J. Wuhan Univ. Technol. Mat. Sci. Edit. 2013, 28, 285-290. [CrossRef]

48. Izaguirre, A.; Lanas, J.; Alvarez, J.I. Characterization of aerial lime-based mortars modified by the addition of two different water-retaining agents. Cem. Concr. Compos. 2011, 33, 309-318. [CrossRef]

49. Shi, C.; Zou, X.W.; Wang, P. Influences of EVA and methylcellulose on mechanical properties of Portland cement-calcium aluminate cement-gypsum ternary repair mortar. Constr. Build. Mater. 2020, 241, 118035. [CrossRef]

50. Powers, T.C.; Willis, T. The air requirement of frost resistant concrete. Proc. Highway Res. Board 1949, $29,184-211$.

51. Bogas, J.A.; de Brito, J.; Ramos, D. Freeze-thaw resistance of concrete produced with fine recycled concrete aggregates. J. Clean. Prod. 2016, 115, 294-306. [CrossRef]

52. Wang, Q.S.; Wang, Q.C.; Zhang, K.; Li, W.L.; Li, J.X. Analysis of Pore Structure and Frost Resistance of Concrete with Different Air Content. B. Chin. Ceram. Soc. 2015, 34, 30-35. [CrossRef]

53. Mazaheripour, H.; Ghanbarpour, S.; Mirmoradi, S.H.; Hosseinpour, I. The effect of polypropylene fibers on the properties of fresh and hardened lightweight self-compacting concrete. Constr. Build. Mater. 2011, 25, 351-358. [CrossRef]

54. Altalabani, D.; Bzeni, D.K.H.; Linsel, S. Mechanical properties and load deflection relationship of polypropylene fiber reinforced self-compacting lightweight concrete. Constr. Build. Mater. 2020, 252, 119084. [CrossRef]

55. Karahan, O.; Atis, C.D. The durability properties of polypropylene fiber reinforced fly ash concrete. Mater. Des. 2011, 32, 1044-1049. [CrossRef] 